\title{
Arpalık Tepe Mağarası Kutsal Alanı’ndan Sikkeler
}

\author{
Votive Coins from Arpalık Tepe Cave Sanctuary
}

\section{Dinçer Savaş LENGER*}

Özet: 1998 yılında Antalya Arkeoloji Müzesi arkeologları tarafından Pisidia Bölgesi’nde, Yumaklar/ Arpalık Tepe'de gerçekleştirilen kazılarda bir mağara kutsal alanı keşfedilmiştir. Adak eşyaları, pişmiş toprak-bronz figürinler, kaplar ve onlara ait parçalar ve diğer sungularla birlikte ele geçen sikkeler, kutsal alanın İ.Ö. VI. yüzyıl ile İ.S. IV. yüzyıl arasında kullanım gördüğüne işaret etmektedir. Mağaranın ağzında bulunan 714 sikkenin dönemlere, darp yerlerine göre çalışılması ve tasnifi bize kutsal alanın kullanım evrelerini ve dini turizm kapsamında insan sirkülasyonuna dair güçlü ipuçları sunmaktadır.

Anahtar sözcükler: Arpalık Tepe, mağara, kutsal alan, adak, sikke, Selge, Pisidia

Özet: During the rescue excavation conducted at Yumaklar/Arpalık Tepe in Pisidia by archeologists from the Antalya Archeology Museum in 1998, a cave sanctuary was discovered. As votive offerings: terracotta and bronze figurines, pottery shards, miniature votives and coins found indicate it was used from the $\mathrm{VI}^{\text {th }}$ century B.C. to the IV ${ }^{\text {th }}$ century A.D. Examination and classification of 714 coins founded at the entrance to the cave according to period, placed mint places and their statistics provide the periods of use of the sacred place and of, the pilgrimage movements during these periods.

Keywords: Arpalık Tepe, cave, sanctuary, votive, coins, Selge, Pisidia

Arpalık Tepe Mağarası, Antalya İli, Serik İlçesi Gebiz Beldesi’ne bağlı Yumaklar Köyü’nde yer almaktadır. Kutsal alan Selge teritoryumu içinde kalan ve Pamphylia Ovası'na 650 metre yükseklikten bakan bir tepe üzerindedir (Fig. 1). Bölge Pisidia'nın güneyiyle Pamphylia arasında sinırda olup (Brandt, 1992; Arena, 2005) Selge ve Pednelissos’a 20 km., Attaleia’ya ise, 53 km. mesafededir (Işın, 2006, 125; 2008, 110; 2010, 1-2).

Kaçak kazı ihbarı üzerine, mağarada, Antalya Arkeoloji Müzesi’nde görevli arkeologlardan Cihan Tibet, Ünal Demirer ve Mustafa Demirel'in denetiminde gerçekleştirilen kurtarma kazılarında tapınağa bırakılmış sayısız adak eşyası (buluntular Prof. Dr. G. Işın tarafından 2006 yılında Yumaklar Arpalık Tepe Küçük Buluntuları: Ön Rapor başlığı altında AST 23 de yayınlanmıştır: bkz. G. Işın, 2006, 125-135; Terrakotta figürinler ise, Terracotta Figurines from Arpalık Tepe in Pisidia: Apollon and the Great Mother goddess in a Cave Sanctuary başlı̆ğ altında $B C H$ Supplement serisinde yer alacaktır) ile birlikte çok sayıda sikke ele geçmiştir. Buluntuların tümü değerlendirildiğinde kutsal alanın İ.Ö. VI. yüzyıl ile İ.S. IV. yüzyıl arasında kullanım gördügü anlaşılmaktadır.

Kutsal alanın ilk evresinde adak eşyalarının mağaranın ağzına bırakıldıkları düşünülmektedir. İkinci evrede mağaranın ağzı dikdörtgen bir temenos duvarı içine alınmış, üçüncü ve son

\footnotetext{
*Yrd. Doç. Dr., Akdeniz Üniversitesi, Edebiyat Fakültesi, Tarih Bölümü, dslenger@akdeniz.edu.tr
} 
evrede ise, üç basamaklı bir krepidomia üzerinde yükselen Dor düzeninde bir tapınak temenos duvarı içine ilave edilmiştir (Işın, 2006, 125; 2010, 2).

Tapınağın naos'unda, döküntü mimarı yapı taşları altında keşfedilen kuyu ve devamında kuzeybatı istikametinde ilerleyen dar tünelin (Tünelin yer yer çökmüş olmasından dolayı sadece 50 metrelik kısmı takip edilebilinmiştir) tapınak ile kutsal mağara arasındaki geçişi sağladığı anlaşılmıştır (Birinci derecede bilgi Antalya Arkeoloji Müzesi 1998 Gebiz Yumaklar, Arpalık Tepe Kurtarma Kazısı Raporu'ndan alınmıştır). Sikkeler diğer adak eşyalarıyla birlikte söz konusu mağaranın giriş kısmında bulunmuşlardır.

İ.S. III. yüzyıla tarihlenen üç kireçtaşından altar üzerinde yer alan yazıtlar sayesinde kutsal alanda Apollon ve Ana Tanrıça'nın eş zamanlı olarak tapınım gördükleri anlaşılmıştır (Işın, 2006,127; 2010, 6).

İ.S. II. yüzyıla tarihlenen, Paulinus adlı bir vatandaşın adadığı ayakta duran chlamys'li, elinde defne dalı tutan Apollon heykelinin yazıtında ise, Büyük Tanrı Mamblasenos adı geçmektedir. Mamblasenos Apollon'un Pisidia dilindeki ismi olabileceği düşünülmektedir (Işın, 2006, 127; 2008, 110; 2010, 5).

Kazılarda toplam 714 sikke gün ışığına çıkartılmıştır. Biri hariç diğer tümü bronzdandır. Sikkelerden 498 tanesi Hellenistik Dönem'e tarihlenir. Roma Dönemi’ne tarihlenen sikke sayısı 114, Geç Roma Dönemi'ne tarihlenenlerin sayısı, sadece 28 adettir. 73 sikke teşhis edilememiştir. İstatiksel açıdan, Hellenistik Dönem'e tarihlenen sikkeler toplamın \% 70’ini oluşturmaktadır. Bunu \% 16'lık oranla Roma eyalet darpları; ardından da \% 4'lük oranla Geç Roma darpları takip eder. Tanımlanamayan sikkeler toplamın \%10’u kadardır.

Otonom ve Roma eyalet sikkeleri basım yerlerine göre tasnif edildiğinde, 572 eserden 499'unun Selge darbı olduğu görülmektedir ki, bu durum genel toplamın \% 87'sine tekabül eder. Geri kalan \% 13'lük dilimi ise, sekiz farklı kentin darpları oluşturur: Perge (33), Sillyon (18), Side (12), Aspendos (4), Etenna (2), Seleukeia (2) ve Pednelissos (1). Perge darpları \% 6'llk oranla Selge sikkelerinden sonra gelirler (Fig. 2).

Otonom darplar tek başlarına değerlendirildiğinde, 498 sikkeden 475’inin Selge'de basıldığı görülür. Oranın bu derecede yüksek oluşu tabiî ki, kutsal alanın Selge teritoryumunda yer almasıyla alakalıdır (Nollé, \& Schindler, 1991, 17-19; Hellenkemper, \& Hild, 2004, 835-838; Arena, 2005, 237-240). 9 sikke Sillyon, 4 sikke ise, Side darbıdır. Onları üçer sikke ile Perge ve Aspendos, ikişer sikkeyle Etenna ve birer sikkeyle Attaleia ve Pednelissos izler.

Kutsal alanın Roma Dönemi’ndeki popülerliğini ve bir dinsel ziyaret merkezi olarak etki alanını gösterebilen eyalet darpları, Hellenistik dönemden çok farklı bir istatistik sunmaktadır. Her yüz sikkeden 41 tanesi Perge darbıdır. Toplam 74 sikkenin 30’u bu kent adına basılmıştır. Sayısal üstünlügünü kaybetmiş olan Selge \% 32'lik bir orana sahiptir ve 24 sikkeyle temsil edilmektedir. Buluntular içerisinde 9 sikkeyle Sillyon \% 12; 8 sikkeyle Side ise, \% 11'lik bir paya sahiptir. Seleukeia 2, Aspendos ise, 1 sikkeyle temsil edilmişlerdir. Sonuçta Roma Dönemi'nde tapınağa bırakılan Selge sikkelerinde \% 63 oranında bir düşüş göze çarpmaktadır. Hellenistik Dönem'de Pisidia Bölgesi'nde lokal bir kült alanı olduğu anlaşllan (Bulunan sikkelerin sadece \% 5'i Pamphylia'dan gelen ziyaretçilere aittir) Arpalık Tepe Mağarası Kutsal Alanı, anlaşılan o ki Roma Dönemi’nde, özellikle de II. yüzyılda daha geniş bir coğrafyada tanınan bilindik bir kült merkezi haline gelmiştir. 100 sikkeden 68'inin Pamphylia'daki kentlere ait olması durumu belgelemektedir.

Geç Roma Dönemi’ne tarihlenen sikkelerin sayısının ise, sadece 28 olması -ki bu da tüm sikkelerin \% 4'üne eşdeğerdir- Hristiyanlığın bölgedeki gelişimi ve popülaritesiyle doğrudan alakalı olmalıdır.

Hem Hellenistik hem de Roma Dönemi buluntuları arasında diğer Pisidia kentlerinin 
sikkelerine rastlanmaması (2 Etenna ve 1 Pednelissos sikkesi dışında) belki de benzer kült alanlarına Pisidia'da sıklıkla rastlanıyor olmasıyla ilişkilendirebilir. Ana Tanrıça'nın dağlardaki mağaralarda yaşadığına duyulan inanç birçok mağaranın zaman içinde kült merkezine dönüşmesine önayak olmuştur (Karayaka, 2007, 21-26; Lydia ve Phrygia'dakiler kutsal alanlar için bk. Ricl, 2003, 77-101). Sıklıkla Meter Oreia ve Meter Theon adıyle anılan tanrıça zaman zaman Meter Potamene, Metaurene, Ouegna, Polyettene, Tymenene, Kadmene ve Agdistis epitheton'ları altında tapınım görmüştür (Vermaseren, 1987, 222-232; Mitchell, 1993, 19-20; Karayaka, 2007, 21-26; 31-32; Efendioğlu, 2010, 31-42).

Pisidia'da, Selge'nin kuzeyinde Tymbriada teritoryumu içerisinde kalan Zindan Mağarası'nda Meter Theon Veginos kültünün tapınım gördüğü bilinmektedir (Dedeoğlu, 2005, 95-102; Takmer, \& Gökalp, 2005, 103-113). Arriasos'un doğusundaki İndağ'da yer alan mağaralar ve yine aynı kentin güneyindeki Yuvacı'dakiler Meter Oreia (Moretti, 1926a, 509-546; Moretti, 1926b, 547554; Karayaka, 2007, 22, 26). Dutalan/Potalın köyü yakınındaki mağaraların ise, Tanrıça Tyriose/Turiose (-a) (Horsley, \& Mitchell, 2000, 92-93) kültüne ev sahipliği ettiği bilinmektedir.

Pamphylia'da ise, en iyi bilinen örnekler Meter Oreia kültünün tapınım gördüğü Karain Mağarası (Şahin, 1991, 126-132; Çizmeli, Öğün, 2011, 97-98) ve Gürman Dağı'dır (Metzger, 1952, 17).

Arpalık Tepe Kutsal Alanı'nda olduğu gibi, birden fazla tanrının bir arada tapınım gördüğü kült merkezleri Pisidia'da sıklıkla karşımıza çıkmaktadır: Tymbriada-Zindan Mağarası'nda, Zeus, Irmak Tanrısı Eurymedon ve Meter Theon (Kaya, \& Mitchell, 1985, 39-55; Dedeoğlu, 2005, 95; Takmer, \& Gökalp, 2005, 102-103); Pisidia Antiokheia'sındaki Augustus Tapınağı'nda Men ve Kybele (Karayaka, 2007, 24-26); Karakuyu'daki Men Tapınağı'nda Demeter ve Men'in (Karayaka, 2007, 24) ortak tapınım gördükleri epigrafik ve arkeolojik veriler ışığında belgelenmiştir.

Sonuç olarak, Arpalık Tepe Mağarası'ndaki kutsal alan, tıpkı aynı bölgedeki TymbriadaZindan Mağarası ve Pamphylia'daki Karain Mağarası gibi kazısı yapılmış ender merkezlerdendir. Adak sikkelerinin ayrıntılı tasnifi, kataloglanması, diğer materyal kültür kalıntılarıyla birlikte istatistiğinin yapılması (metale, nominaline, döneme, darp eden otoriteye göre), bölgede tapınım gören bir kült merkezin insan sirkülasyonunu 'süreç bă̆ımlı' metodolojiyle analiz etmeye ve kutsal alanın kültür tabakalarını daha iyi anlamamıza ve yorumlamamıza yardımcı olacaktır. 


\section{KAYNAKÇA}

Arena, G. (2005). Cittá di Panfilia e Pisidia sotto il Dominio Romano. Catania. Edizioni del Prisma.

Brandt, H. (1992). Gesellschaft und Wirtschaft Pamphyliens und Pisidiens in Altertum. Bonn: AMS 7.

Çizmeli, Öğün, Z. (2011). Karain ve Suluin Mağaralarında Bulunan Sikkeler. Işın Yalçınkaya’ya Armağan.

Ed. H. Taşkıran, M. Kartal, K. Özçelik, M. B. Kösem, \& G., Kartal. Ankara: Bilgin Kültür Sanat.

Dedeoğlu, J. (2005). The Sanctuary at Zindan Mağarası in the Light of the New Archeological Evidence. Gephyra, 2, 95-102. İstanbul.

Efendioğlu, T. (2010). Likya'da Yerel Tanrı ve Tanrıçalar. İstanbul: Arkeoloji ve Sanat Yayınları.

Hellenkemper, H., \& Hild, F. (2004). Tabula Imperii Byzantini 8. Lykien und Pamphylian. Wien. Verlag der Österreichen Akademie der Wissenschaften.

Horsley, G. R. H., \& Mitchell, S. (2000). The Inscription of Central Pisidia. IK 57. Bonn: Dr. R. Habelt GMBH.

Işın, G. (2006). Yumaklar Arpalık Tepe Küçük Buluntuları: Ön rapor. AST, 23/2, 125-135. Ankara.

Işın, G. Terracotta Figurines from Arpalık Tepe in Pisidia: Apollo and the Great Mother Goddess in a Cave Sanctuary. Suppléments du BCH, (Ed. E. Laflı, \& A. Müller), Figurines de tere cuite en Méditerranée orientale grecque et romaine. Production et Diffusion, iconographie et Fonction. Colloque international, 2-6 June 2007/İzmir, Turquie. (Yayın aşamasında).

Işın, G. (2008). The Cult of Apollo in Southern Pisidia and Apollon Sideiton. Ege Üniversitesi, Arkeoloji Dergisi, 2008(2),107-115. I. Uluslararası Antik Dönemde Kehanet ve Apollon’un Anadolu Kültleri Sempozyum Bildirileri 17-20 Ağustos 2005, Ege Üniversitesi. İzmir.

Işın, G. (2010). The Great God Mamblasenos/Apollon. Bolletino di Archeologia on Line I, 2010, 1-7. (Volume speciale).

Karayaka, N. (2007). Helenistik ve Roma döneminde Pisidia Tanrıları. İstanbul: Ege Yayınları.

Kaya, D., \& Mitchell, S. (1985). The Sanctuary of the God Eurymedon at Tymbriada. AS, 35, 39-55. London.

Metzger, H. (1952). Tête en terre cuite du Musée d'Adalia. REA, 54, 13-17. Paris.

Mitchell, S. (1993). Anatolia, Land, Men, and Gods in Asia Minor, vol. II: The Rise of the Church. Oxford: Clarendon Press.

Moretti, G. (1926a). In-Daghinda Qogia. ASAtene, VI-VII, 509-46. Roma

Moretti, G. (1926b). Le Grotte Sacree di Iuvadja. ASAtene, VI-VII, 547-54. Roma.

Nollé, J., \& Schindler, F. (1991). Die Inschriften von Selge, IK, 37. Bonn: Dr. R. Habelt GMBH.

Ricl, M. (2003). Society and Economy of Rural sanctuaries in Roman Lydia and Phrygia. EA, 35, 77-101. Bonn.

Şahin, S. (1991). 5. Meter Oreia von Karain/Antalya: Eine Grottengöttin in Sudkleinasien. Bemerkungen zu lykischen und pamphylischen Inschriften, $E A, 17,126-32$. Bonn.

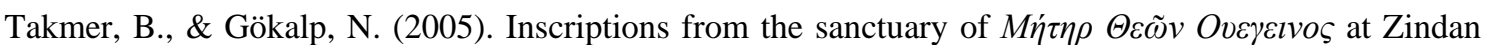
Mağarası I. Gephyra, 2, 103-113. İstanbul.

Tibet, C., Demirer, Ü., \& Demirel, M. (1998). Antalya Müzesi 1998, Gebiz Yumaklar Arpalık Tepe Kurtarma Kazısı Raporu (Yayınlanmamış).

Vermaseren, M. J. (1987). Corpus Cultus Cybelae Attidisque (CCCA) I. Asia Minor. Lieden: Brill. 


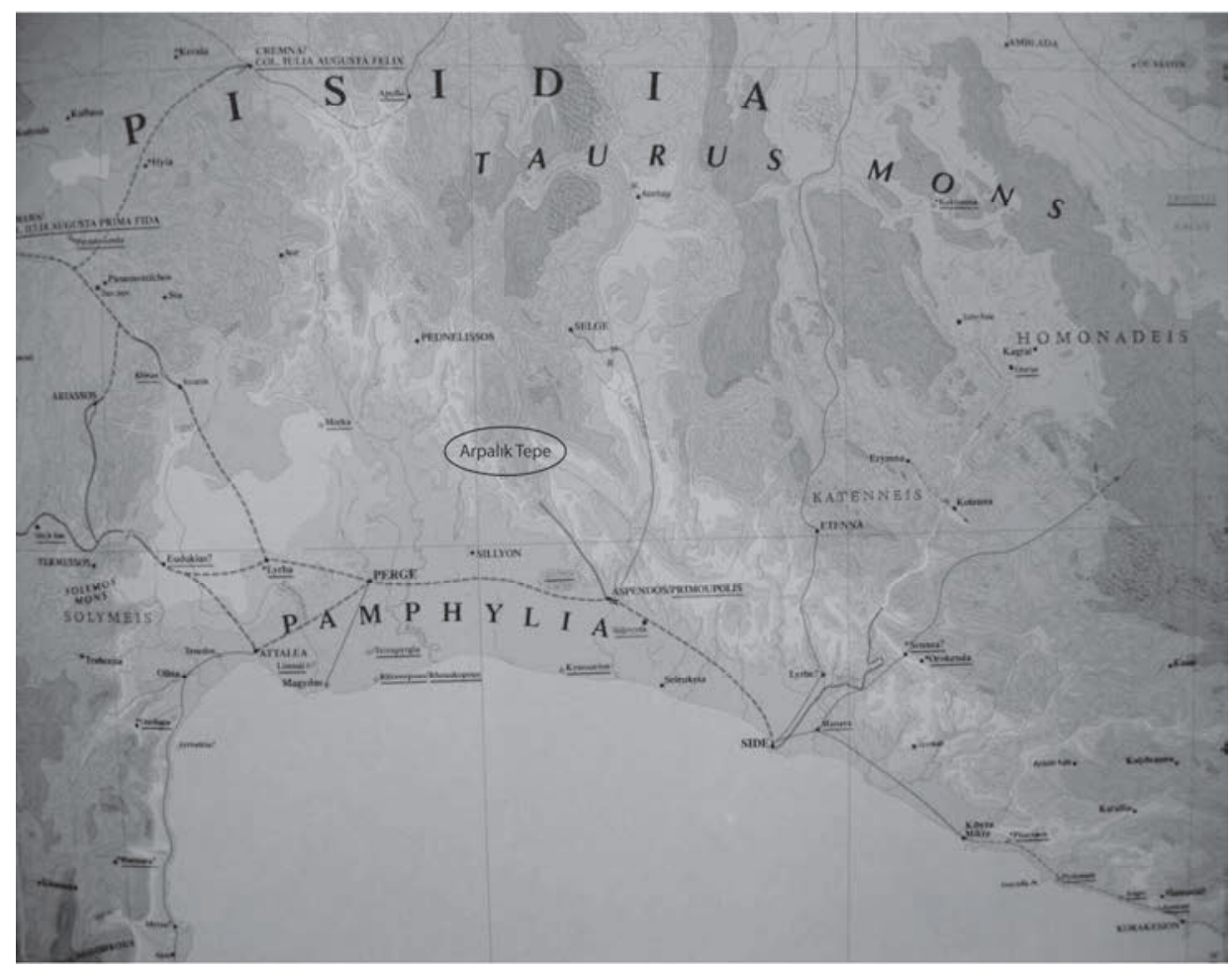

Figür 1. Arpalık Tepe, Genel Görünüm (Talbert, 2000, 65).

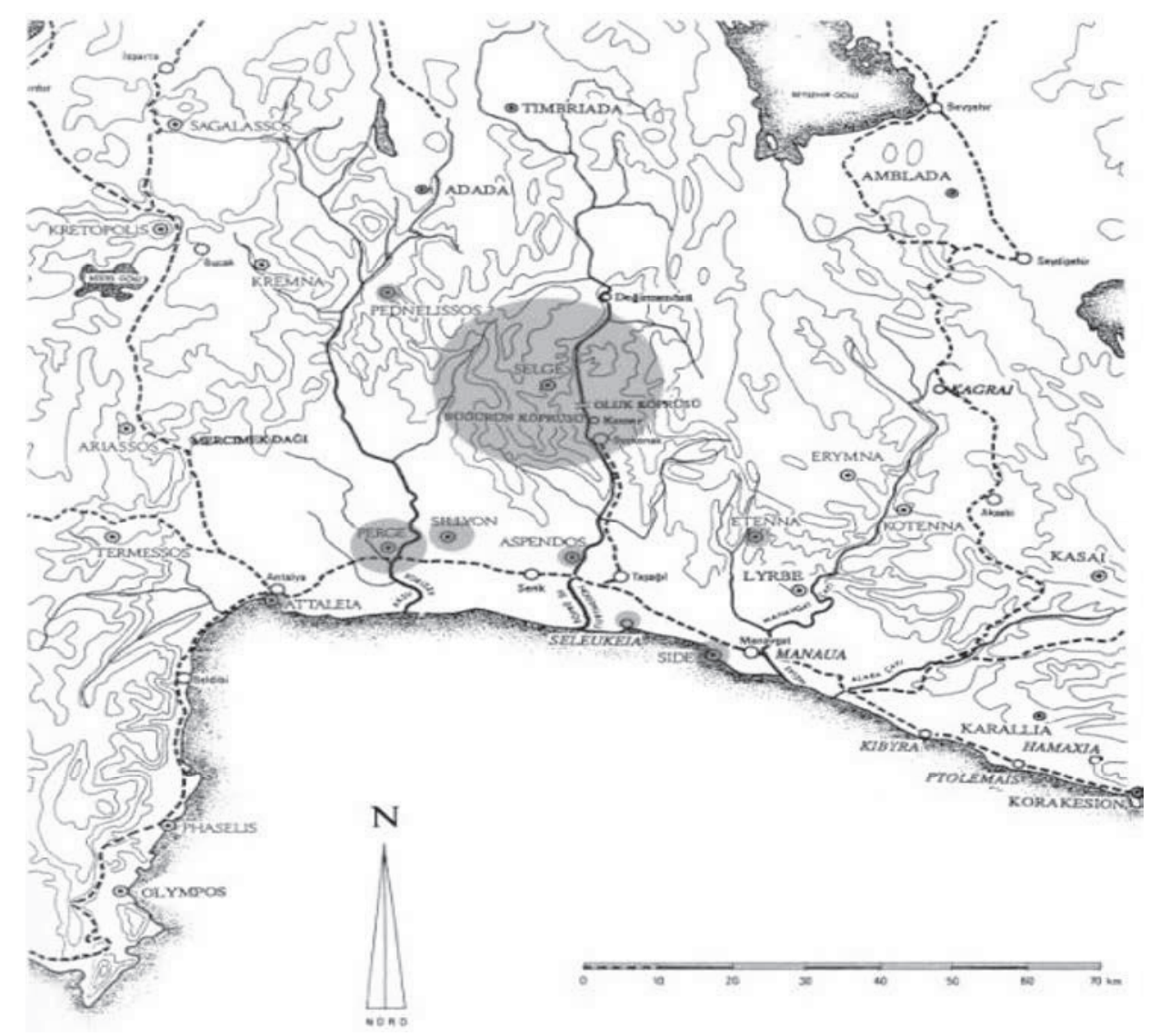

Figür 2. Kutsal Alanda Bulunan Sikkelerin Darp Yerlerine Göre Dağılımı. 